\title{
Corrigendum to "Cubic Bezier Curve Approach for Automated Offline Signature Verification with Intrusion Identification"
}

\author{
Arun Vijayaragavan, ${ }^{1}$ K. L. Shunmuganathan, ${ }^{2}$ and J. Visumathi ${ }^{3}$ \\ ${ }^{1}$ Department of Computer Science and Engineering, Sathyabama University, Chennai, Tamil Nadu, India \\ ${ }^{2}$ Department of Computer Science and Engineering, R.M.K Engineering College, Chennai, Tamil Nadu, India \\ ${ }^{3}$ Department of Computer Science and Engineering, Jeppiaar Engineering College, Chennai, Tamil Nadu, India \\ Correspondence should be addressed to J. Visumathi; jsvisu@gmail.com \\ Received 9 July 2015; Accepted 15 September 2015 \\ Copyright (c) 2015 Arun Vijayaragavan et al. This is an open access article distributed under the Creative Commons Attribution \\ License, which permits unrestricted use, distribution, and reproduction in any medium, provided the original work is properly \\ cited.
}

In the paper titled "Cubic Bezier Curve Approach for Automated Offline Signature Verification with Intrusion Identification" [1], the ordering of the authors was incorrect as it is corrected above. Also, the affiliation of the first author was "Department of Information Technology, R.M.D. Engineering College, Chennai, Tamil Nadu, India" and it is corrected as above.

\section{References}

[1] A. Vijayaragavan, J. Visumathi, and K. L. Shunmuganathan, "Cubic bezier curve approach for automated offline signature verification with intrusion identification," Mathematical Problems in Engineering, vol. 2014, Article ID 928039, 7 pages, 2014. 


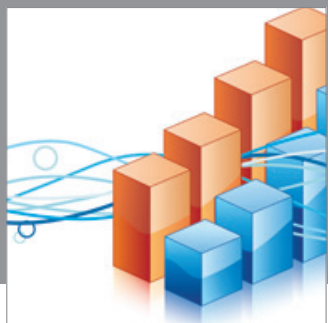

Advances in

Operations Research

mansans

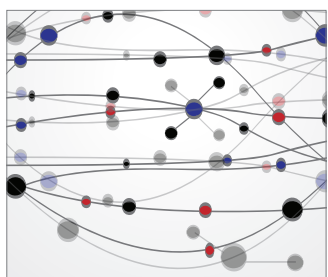

The Scientific World Journal
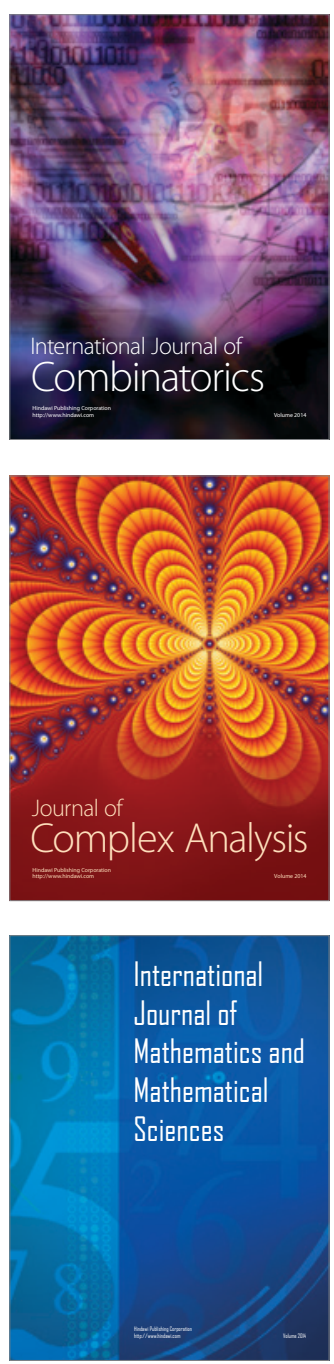
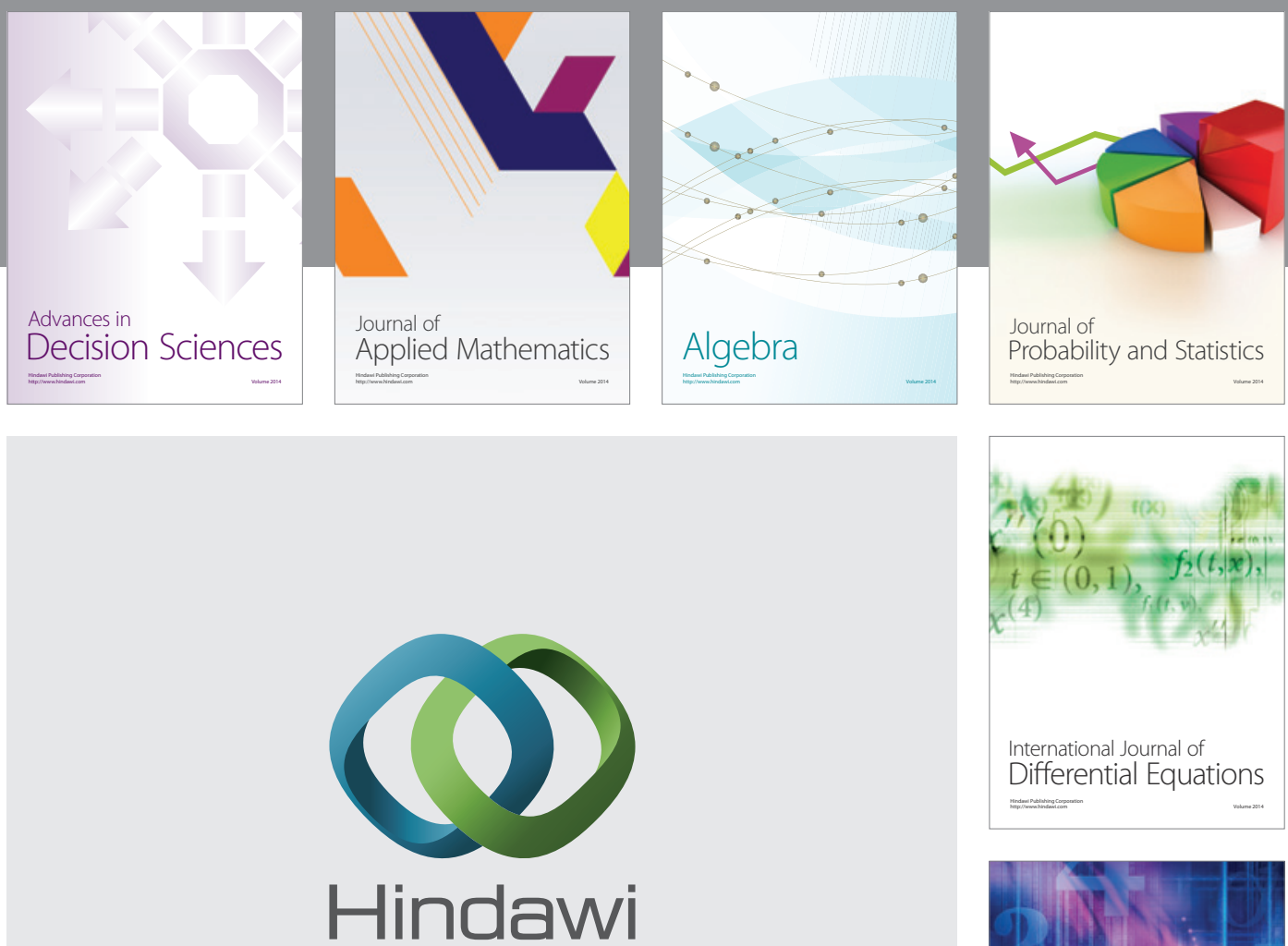

Submit your manuscripts at http://www.hindawi.com
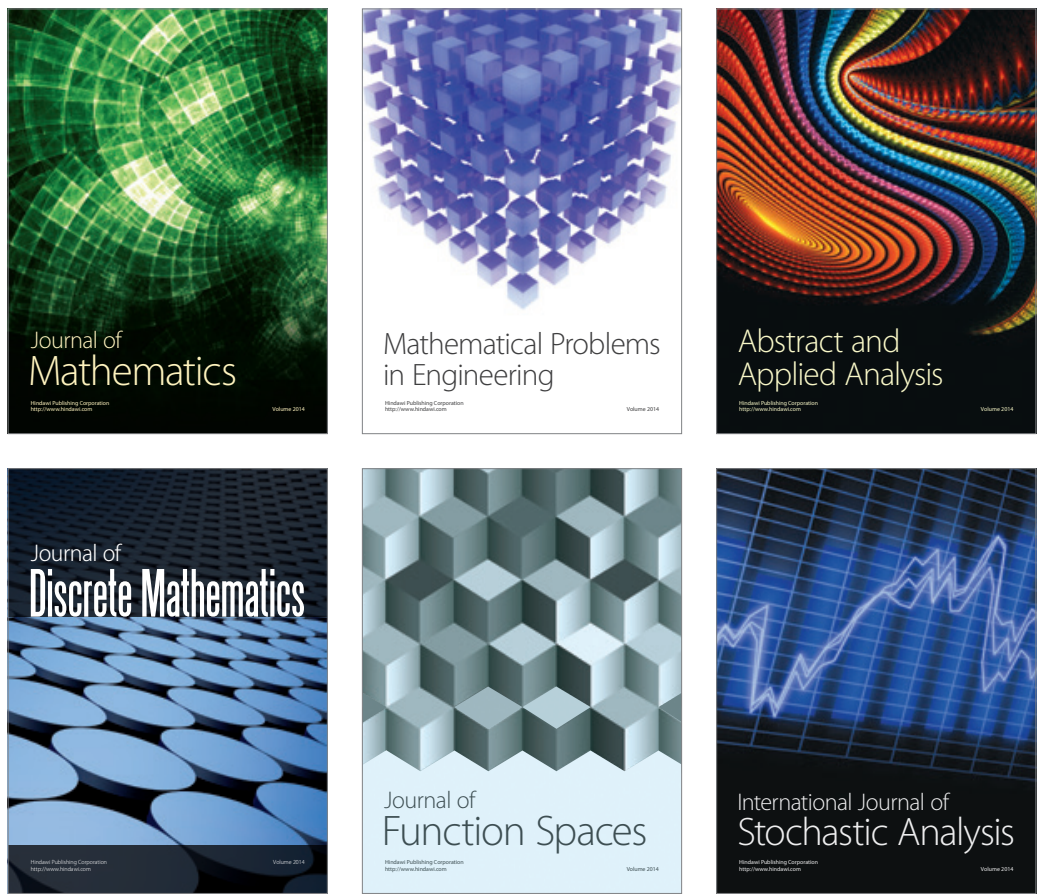

Journal of

Function Spaces

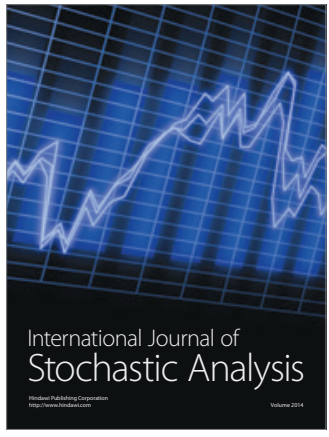

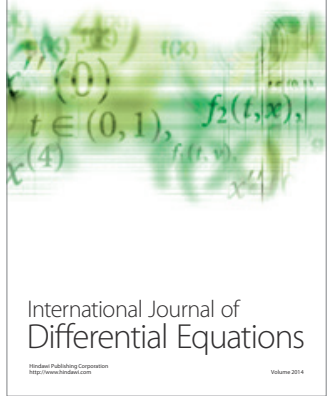
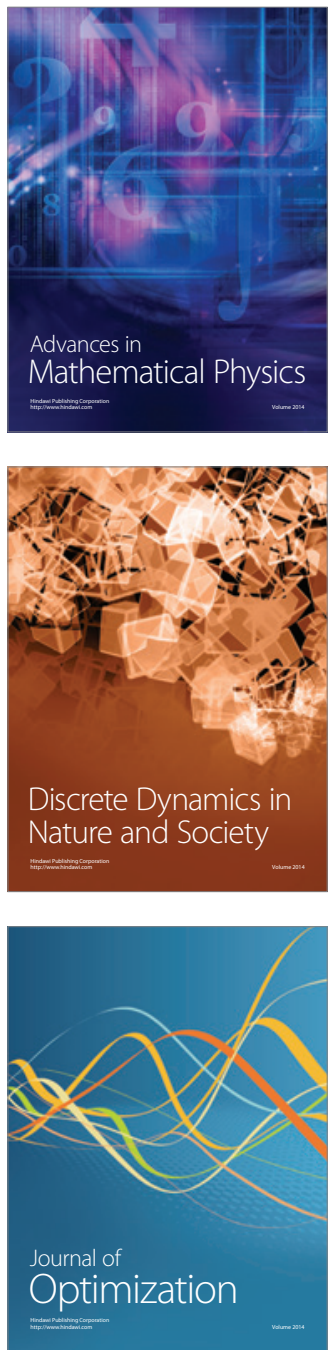